\title{
Fine genetic mapping of the Co locus controlling columnar growth habit in apple
}

\author{
Tuanhui Bai · Yuandi Zhu • Felicidad Fernández-Fernández • \\ Johan Keulemans · Susan Brown · Kenong Xu
}

Received: 31 December 2011/Accepted: 5 April 2012/Published online: 17 April 2012

(C) Springer-Verlag 2012

\begin{abstract}
Tree architecture is an important, complex and dynamic trait affected by diverse genetic, ontogenetic and environmental factors. 'Wijcik McIntosh', a columnar (reduced branching) sport of 'McIntosh' and a valuable genetic resource, has been used intensively in apple-breeding programs for genetic improvement of tree architecture. The columnar growth habit is primarily controlled by the dominant allele of gene Co (columnar) on linkage group-10. But the Co locus is not well mapped and the $C o$ gene remains unknown. To precisely map the $C o$ locus and to identify candidate genes of $C o$, a sequence-based approach using both peach and apple genomes was used to develop new markers linked more
\end{abstract}

Communicated by S. Hohmann.

T. Bai and Y. Zhu contributed equally to this work.

Electronic supplementary material The online version of this article (doi:10.1007/s00438-012-0689-5) contains supplementary material, which is available to authorized users.

T. Bai $\cdot$ Y. Zhu $\cdot$ S. Brown $\cdot$ K. Xu (ه)

Department of Horticulture, Cornell University,

New York State Agricultural Experiment Station,

Geneva, NY 14456, USA

e-mail: kx27@cornell.edu

Present Address:

T. Bai

College of Horticulture, Henan Agricultural University,

Zhengzhou 45002, Henan, People's Republic of China

F. Fernández-Fernández

East Malling Research (EMR), New Road, East Malling,

Kent ME19 6BJ, UK

J. Keulemans

Laboratory for Fruit Breeding and Biotechnology,

Department of Biosystems, Faculty of Bioscience Engineering,

University of Leuven, 3001 Heverlee, Belgium tightly to $C o$. Five new simple sequence repeats markers were developed (C1753-3520, C18470-25831, C6536-31519, C7223-38004 and C7629-22009). The first four markers were obtained from apple genomic sequences on chromosome-10, whereas the last (C7629-22009) was from an unanchored apple contig that contains an apple expressed sequence tag CV082943, which was identified through synteny analysis between the peach and apple genomes. Genetic mapping of these five markers in four $F_{1}$ populations of 528 genotypes and 290 diverse columnar selections/cultivars ( 818 genotypes in total) delimited the $\mathrm{Co}$ locus in a genetic interval with $0.37 \%$ recombination between markers $\mathrm{C} 1753-3520$ and $\mathrm{C} 7629$ 22009. Marker C18470-25831 co-segregates with $C o$ in the 818 genotypes studied. The Co region is estimated to be $193 \mathrm{~kb}$ and contains 26 predicted gene in the 'Golden Delicious' genome. Among the 26 genes, three are putative LATERAL ORGAN BOUNDARIES (LOB) DOMAIN (LBD) containing transcription factor genes known of essential roles in plant lateral organ development, and are therefore considered as strong candidates of $C o$, designated $M d L B D 1, M d L B D 2$, and $M d L B D 3$. Although more comprehensive studies are required to confirm the function of MdLBD1-3, the present work represents an important step forward to better understand the genetic and molecular control of tree architecture in apple.

Keywords Apple - Columnar growth habit . Co (columnar) - Fine mapping - Synteny $\cdot$ LATERAL ORGAN BOUNDARIES (LOB) DOMAIN (LBD)

\section{Introduction}

Apple (Malus $\times$ domestica Borkh, family Rosaceae) is one of the most important fruit crops in the world. Based on the 
stats of the Food and Agriculture Organization (FAO), over 69.8 million metric tons of apple fruits were produced by 93 countries worldwide in 2008. Apple tree architecture, which varies greatly not only among cultivars but also within a tree along the course of growth and development, is an important complex trait affecting planting density, fruit quality, orchard management and production (Hemmat et al. 1997; Kenis and Keulemans 2007). Complex genetic, ontogenetic and environmental factors play a role in determining apple tree architecture and many quantitative trait loci (QTLs) of significant effect on tree form have been detected (Kenis and Keulemans 2007; Segura et al. 2008, 2009). Despite the tremendous variations, apple tree architecture has been categorized into four types based on its overall growth habit and fruiting type: columnar (I), spur (II), standard (III) and tip bearing (IV) (Costes et al. 2006; Lespinasse and Delort 1986; Pereira-Lorenzo et al. 2009).

The columnar growth habit in apple was initially discovered as a sport of 'McIntosh' (Lapins 1969). This mutant, called 'Wijcik McIntosh', has short internodes, a thick stem with little difference in diameter between the top and the base and a reduced plant height and branching (Lapins 1976). These characteristics of 'Wijcik McIntosh' have been viewed highly valuable in apple-breeding programs for the genetic improvement of tree architecture. One of the modern apple breeding goals is to produce apple cultivars with columnar growth habit for growing apple in high-density orchards (Kenis and Keulemans 2007; Moriya et al. 2009; Tobutt 1984). Due to its reduced branching, columnar trees require minimal pruning and training, and genetic selection of columnar form would allow adequate light penetration to fruits and leaves.

Some physiological studies have focused on understanding how the variations at the plant hormonal levels may associate with the types of tree architecture. Among the four major phytohormones examined, i.e., Auxins, ABA (abscisic acid), cytokinins and GA (gibberellins), higher levels of cytokinins, such as zeatin-like growth substances, appeared to be most consistently correlated with columnar growth habit (Looney and Lane 1984; Watanabe et al. 2004, 2008). These observations are in accordance with the in vitro comparisons of tissue tolerance to various cytokines or cytokinin-like compounds, such as BA (benzyl adenine), kinetin, 2iP (2-isopentenyladenine), TDZ ( $N$-phenyl- $N$-1,2,3-thiadizol-5-ylurea). Among the three strains of 'McIntosh', 'Wijcik McIntosh' was more tolerant to high cytokinin than either 'Macspur' (intermediate tolerance), or 'McIntosh' (died) (Lane et al. 1982; Sarwar et al. 1998). Higher levels of IAA (indole-3acetic acid) in subapical parts of shoot in early June and July and in columnar types were reported (Watanabe et al. 2004, 2008). In addition, IAA concentrations of columnar were significantly higher in apical shoots than in lateral shoots while there was no such difference in standard (Watanabe et al. 2006). The role of ABA and GA on tree architecture was not as certain as that of cytokinins and IAA. However, the ratio of IAA/cytokinin was lower in columnar types, and IAA/ABA and $\mathrm{GA}_{3} / \mathrm{IAA}$ were higher in tip-bearing types, suggesting the existence of combined roles of two or more plant hormones in shaping apple tree architecture (Bendokas and Stanys 2009). Although these physiological studies are helpful in explaining the strong apical dominance and apical control in columnar and provide useful information for knowing which plant hormone(s) might be more important in regulating apple-tree growth habit and fruiting types, our understanding of the underlying physiology remains unclear.

The columnar growth habit was suggested to be controlled by a single dominant gene, Co (columnar), with one or more modifiers to account for a consistent deficiency of columnar seedlings as expected from the 1 (columnar): 1 (standard) ratio (Lapins 1976). The Co locus was first mapped to linkage group (LG) 10 of 'Wijcik McIntosh' using a set of random amplified polymorphic DNA (RAPD) markers (Conner et al. 1997, 1998) and an simple sequence repeats (SSR) marker $\mathrm{SSR}^{\mathrm{co}}$ developed from one of these RAPDs, OA11 1000 (Hemmat et al. 1997). More recently, the columnar trait has been investigated using various columnar cultivars, e.g. 'Telamon', 'Tuscan' and 'Totem', or breeding selections derived from 'Wijcik McIntosh' (Fernandez-Fernandez et al. 2008; Kenis and Keulemans 2007; Kim et al. 2003; Moriya et al. 2009; Tian et al. 2005; Zhu et al. 2007), and the general map position of the Co locus on LG10 has been consistent despite a lack of common markers for direct comparison and alignment. However, the precise position of $C o$ is less clear. On one hand, the Co locus was mapped to the same interval between two sequence-characterized amplified regions (SCAR) markers SCAR682 and SCAR216 in two independent reports (Moriya et al. 2009; Tian et al. 2005). On the other hand, the Co locus was placed in two presumably adjacent intervals: one between SSR markers CH02c11 and CH03d11 (Fernandez-Fernandez et al. 2008), the other between CH03d11 and Hi01a03 (Moriya et al. 2009). Nevertheless, efforts toward isolating the Co gene have been announced (Baldi et al. 2009).

Peach (Prunus persica Batsch) is another tree fruit genera in Rosaceae and the pillar growth habit in peach is the most comparable trait with columnar in apple. Peach pillar (PI), also known as columnar or broom, is controlled by a recessive allele at the $b r$ locus (Chaparro et al. 1994; Rajapakse et al. 1995; Scorza et al. 2002; Werner and Chaparro 2005) on peach LG-2 (Sajer et al. 2011; Sosinski et al. 2000). Peach chromosome-2 shows strong synteny with apple chromosomes 1, 2 and 7 (Illa et al. 2011), but 
not with apple chromosome-10 where the $C o$ locus resides. In combination with the contrasting gene action, i.e., dominant columnar $(\mathrm{Co})$ versus recessive pillar $(\mathrm{br})$, this synteny information enhances the impression that genes $C o$ and $b r$ are different. The objectives of this study were to fine map the Co locus to clarify the genetic position of $C o$ by combining genetic materials developed in three applebreeding programs, and more importantly, to provide a foundation for the ultimate identification of the gene(s) underlying $C o$ for better understanding the genetic and molecular control of tree architecture in tree fruits.

\section{Materials and methods}

Plant materials

A total of 818 genotypes, including 528 trees in four segregating populations and 290 columnar selections/cultivars, were used (Table 1; Online resources 1,2). The first population $(\mathrm{FN})$, consisted of $271 \mathrm{~F}_{1}$ individuals, was derived from a cross of 'Fuji' (coco, standard growth habit) $\times$ NYCO7-G (Coco, a columnar selection from 'Wijcik McIntosh' $\times$ 'Suncrisp'). Population FN was planted in 2001 and grown on their seedling roots in Geneva, New York. The second population (TB) of $222 \mathrm{~F}_{1}$ trees was derived from a cross of 'Telamon' (Coco, a columnar cultivar from 'Wijcik McIntosh' $\times$ 'Golden Delicious') $\times$ 'Braeburn' (coco, standard growth habit). The TB population has been used in several studies (Davey et al. 2006; Kenis and Keulemans 2005, 2007; Kenis et al. 2008), and was created by the lab of Dr. Johan (Wannes) Keulemans, University of Leuven, Belgium. In this population, two vegetative clones per genotype were grafted on apple rootstock B.9 and planted in an orchard at Geneva, New York, in 2008. The third [Pinova $($ coco $) \times$ NYCO7-G $($ Coco $)$, or PN] and the fourth ['Fiesta' (coco $) \times$ 'Totem '(Coco), or $\mathrm{F} \times \mathrm{T}]$ are small populations of only 24 and $11 \mathrm{~F}_{1}$ trees, respectively. Both seed parents are cultivated varieties of standard tree form. 'Totem' (SA572-2), an ornamental columnar apple also known as 'Maypole 2000', is of complex interspecific origin (Fernandez-Fernandez et al. 2008). Population PN was also grown on their seedling roots, and was planted in the same orchard as population $\mathrm{FN}$ in 2001. The fourth population $(\mathrm{F} \times \mathrm{T})$ was a subset of the population used in Fernandez-Fernandez et al. (2008) and was grown in East Malling, UK. Population $\mathrm{F} \times \mathrm{T}$ was not used in the initial mapping of $C o$, but assayed together with the columnar selections/cultivars described below.

The 290 columnar selections were developed by three apple breeding programs with 34 from Cornell University (CU), Geneva, New York, 121 from China Agricultural University (CAU), Beijing, China, and 135 from East Malling Research (EMR), Kent, UK. The 34 CU columnar selections (Online resource 1) include 31 genotypes from six different crosses and three named columnar cultivars: 'Irish Spire', 'Tuscan' ('Wijcik McIntosh' × 'Greensleeves') and 'Telamon'. The 121 CAU selections were

Table 1 List of $F_{1}$ populations and columnar selections/cultivars

\begin{tabular}{|c|c|c|c|c|c|c|c|}
\hline $\begin{array}{l}\text { Population/ } \\
\text { selections }\end{array}$ & Description & Planting location & $\begin{array}{l}\text { Number } \\
\text { of trees }\end{array}$ & Columnar & Standard & Unclear & $P\left(\chi^{2}\right)$ \\
\hline FN & $\begin{array}{c}\text { Fuji } \times \text { NYCO7-G }(\text { Wijcik } \\
\text { McIntosh } \times \text { Suncrisp })\end{array}$ & $\begin{array}{l}\text { Cornell University, } \\
\text { Geneva, NY }\end{array}$ & 271 & 156 & 104 & 11 & $0.001(10.40)$ \\
\hline TB & $\begin{array}{l}\text { Telamon }(\text { Wijcik } \\
\text { McIntosh } \times \text { Golden } \\
\text { Delicious }) \times \text { Braeburn }\end{array}$ & $\begin{array}{l}\text { Cornell University, } \\
\text { Geneva, NY }\end{array}$ & 222 & 105 & 113 & 4 & $0.59(0.29)$ \\
\hline PN & $\begin{array}{l}\text { Pinova } \times \text { NYCO7-G }(\text { Wijcik } \\
\text { McIntosh } \times \text { Suncrisp })\end{array}$ & $\begin{array}{l}\text { Cornell University, } \\
\text { Geneva, NY }\end{array}$ & 24 & 16 & 7 & 1 & $0.06(3.52)$ \\
\hline $\mathrm{F} \times \mathrm{T}$ & Fiesta $\times$ Totem & $\begin{array}{l}\text { East Malling Research, } \\
\text { Kent, UK }\end{array}$ & 11 & 5 & 6 & 0 & $0.76(0.09)$ \\
\hline $\mathrm{CU}^{\mathrm{a}, \mathrm{b}}$ & Columnar selections & $\begin{array}{l}\text { Cornell University, } \\
\text { Geneva, NY }\end{array}$ & 34 & 34 & 0 & 0 & \\
\hline CAU & $\begin{array}{r}\text { Columnar selections } \\
(\text { Fuji } \times \text { Telamon })\end{array}$ & $\begin{array}{l}\text { China Agricultural } \\
\text { University, Beijing, } \\
\text { China }\end{array}$ & 121 & 121 & 0 & 0 & \\
\hline $\mathrm{EMR}^{\mathrm{a}}$ & Columnar selections & $\begin{array}{l}\text { East Malling Research, } \\
\text { Kent, UK }\end{array}$ & 135 & 135 & 0 & 0 & \\
\hline Total & & & 818 & 572 & 230 & 16 & \\
\hline
\end{tabular}

$\chi^{2}$, Chi-square critical value $(\mathrm{CV})$ calculated with the expected ratio $1: 1 ; P$, cumulative probability for $\chi^{2}>\mathrm{CV}$

${ }^{\text {a }}$ Parentage of individual selections were listed in Online resources 1,2

b Including three columnar cultivars 
obtained from a population of more than 800 seedlings developed from a single cross of 'Fuji' $\times$ 'Telamon' made in 1995 (Zhu et al. 2007). The 135 EMR selections were derived from a large number of crosses and are diverse, but their columnar trait is all of 'Wijcik McIntosh' origin (Online resource 2). In addition, population GMAL 4595 ('Royal Gala' $\times$ PI 613988) of $188 \mathrm{~F}_{1}$ trees, in which both parental genetic maps were developed (Wang et al. 2012), was used to map new markers to the $C o$ region, such as marker CV082943STS, that were developed based on synteny approach using the peach genome, but could not be directly mapped in the Co mapping populations, or out of the Co region, such as markers C19509.316 and C7156.181, that were developed from apple genomic sequences on chromosome-10 supposed to be physically close to $\mathrm{Co}$.

Growth habit evaluation

Growth habit was visually evaluated based on thickness of stem, number and crotch angle of lateral branches on the main axis and internode length. Compared with trees of standard growth habit, columnar trees have a thicker main stem characterized by similar diameter at the tip and the base, fewer lateral branches with narrower crotch angles, and shorter internodes (Hemmat et al. 1997; Kenis and Keulemans 2007). In the FN, TB and PN populations, trees were evaluated in 2009 and 2010 and classified into two categories: columnar and standard. Population $\mathrm{F} \times \mathrm{T}$ had already been evaluated (Fernandez-Fernandez et al. 2008). Columnar and standard selections were classified by the apple breeder.

\section{Genomic DNA extraction and PCR amplification}

Genomic DNA isolation, PCR and SSR analyses were conducted as described previously (Wang et al. 2012). Young leaves were collected and ground using a TissueLyser II (Qiagen, Valencia, CA). Genomic DNA was extracted using the cetyltrimethylammonium bromide (CTAB) method according to Doyle and Doyle (1987) and Cullings (1992). PCR amplification of SSR markers was conducted in a volume of $20 \mu \mathrm{l}$ containing $50 \mathrm{ng}$ of genomic DNA, $1 \times$ PCR buffer, $0.2 \mathrm{mM}$ of dNTP, $2 \mathrm{mM}$ $\mathrm{MgCl}_{2}, 0.5 \mu \mathrm{M}$ of each primer and $0.5 \mathrm{U}$ of Taq DNA polymerase (Promega, Madison, WI, USA). The thermal cycling conditions include: an initial cycle of $5 \mathrm{~min}$ at $95{ }^{\circ} \mathrm{C}, 35$ cycles of $30 \mathrm{~s}$ at $94{ }^{\circ} \mathrm{C}, 30 \mathrm{~s}$ at $55^{\circ} \mathrm{C}, 90 \mathrm{~s}$ at $72{ }^{\circ} \mathrm{C}$, and a final cycle of $5 \mathrm{~min}$ at $72{ }^{\circ} \mathrm{C}$. PCR for RAPD analysis was conducted according to Hemmat et al. (1997). PCR products were analyzed on a $6.0 \%$ non-denaturing polyacrylamide gel or a $2.0 \%$ agarose gel. The ethidium bromide-stained gel images were photographed with a
UVP DigiDoc-It Imaging System (UVP97010501, Fisher Scientific, Pittsburgh, PA) and segregating bands were recorded manually for linkage analysis.

Initial mapping of the Co locus

Eighteen published markers (nine SSRs, three SCARs and six RAPDs) were selected (Fernandez-Fernandez et al. 2008; Hemmat et al. 1997; Kim et al. 2003; Liebhard et al. 2002; Silfverberg-Dilworth et al. 2006; Tian et al. 2005), and their names and primer sequences are presented in Online resource 3. Association of the 18 markers with $\mathrm{Co}$ was first screened with ten columnar and ten standard segregants from population 'Fuji' $\times$ NYCO7-G, or nine apple varieties/selections that include four columnar ['Wijcik McIntosh', NYCO7-G, NYCO16-C ('Pinova' $\times$ NYCO7-G) and NYCO17-H ('Wijick McIntosh' $\times$ 'Redfree')] and five standard ('Fuji', 'Pinova', 'Gala,' PI 613988 and G.41). Markers that show strong association with $C o$ were further applied to the entire mapping populations of 'Fuji' $\times$ NYCO7-G $(F N)$, 'Telamon' $\times$ 'Braeburn' (TB), and 'Pinova' $\times$ NYCO7-G (PN). Genetic linkage analysis for initial mapping of $C o$ was conducted with JoinMap 3.0 (Van Ooijen and Voorrips 2001) by pooling the marker and growth habit data from populations FN, TB and PN.

\section{Molecular marker development and analysis}

The draft sequences of the peach and apple genomes were released in April 2010 and August 2010 (Velasco et al. 2010), respectively. To take advantages of these genomic resources, a genome sequence-based marker development approach in combination with synteny analysis was used. DNA sequences of the six confirmed Co-linked markers (AU223548, SCAR682, CH03d11, EMPc105, Hi01a03 and Hi01b01) were obtained from either GenBank or HiDRAS (http://www.hidras.unimi.it/) (Online resource 3), and initially were used to search the peach genome and then the apple genome. The objective was to establish the corresponding relationships between the markers and their DNA sequences in the peach and apple genomes so that the general region of $\mathrm{Co}$ could be physically localized for developing new markers closer to $\mathrm{Co}$.

Basic local alignment search tool (BLAST) search against the peach genome at the genome database for rosaceae (GDR) (http://www.rosaceae.org) using the five published markers (AU223548, SCAR682, CH03d11, EMPc105 and Hi01a03) revealed that there was not a single significant hit for marker Hi01a03. However, sequences with high similarities to the first four were identified in a region of $773 \mathrm{~kb}$ from 18,683 to $19,456 \mathrm{~kb}$ in Scaffold-8 (Table 2). To develop new SSR markers, 
DNA sequence of $714 \mathrm{~kb}(19,286-20,000 \mathrm{~kb})$ on Scaffold8 that contains similar sequences for markers $\mathrm{CH} 03 \mathrm{~d} 11$ and EMPc105 were downloaded, and screened for SSR motifs (eight or more di-nucleotide repeats; or six or more trinucleotide repeats) using the web-based program BatchPrimer3 (http://probes.pw.usda.gov/batchprimer3/index. html) (You et al. 2008). To utilize the high transferability of gene-based markers, SSRs covered by predicted peach genes were identified by their genome position coordinates. These peach predicted SSR containing genes were used to BLAST search GenBank for Malus ESTs of highest sequence similarities. The resulting Malus ESTs were analyzed with BatchPrimer3 again for SSRs, leading to selection of six Malus ESTs or Unigenes that are presumably scattered over the Co region. Six primer pairs were designed (Online resource 4) and assayed with the set of nine columnar and standard varieties/selections mentioned above for mapping.

Similar BLAST searches against the apple genome at GDR indicated that the five published markers were all found in contigs of chromosome-10, as expected, but spreading over 2,926 kb (Table 2). However, the Co region between markers EMPc105 and Hi01a03 is estimated to be $1,354 \mathrm{~kb}$ (Table 2). DNA sequences of representative contigs in this broad $C o$ region as well as those in an unanchored region but mapped to the $C o$ region by marker CV082943STS were downloaded and analyzed for the presence of SSRs. Primer design and analysis were similar to that described above (Online resource 5).

Fine map construction and estimation of the physical size at the Co locus

The mapping populations and columnar selections/cultivars (818 genotypes in total) were analyzed with the two markers, SCAR682 and Hi01a03, which flank the Co locus (Fig. 1a) to identify informative recombinants. Recombinant plants were then genotyped with newly developed SSR markers for fine map construction around the Co locus. The physical size of the $C o$ locus was estimated with physical distance $(\mathrm{kb})$ between two markers (C1753-3520 and C7629-22009) immediately flanking $C o$ in the homologous genomic region of 'Golden Delicious' available at GDR or The Istituto Agrario San Michele all'Adige (http://genomics.research.iasma.it/index.html).

Gene prediction and phylogenetic analysis

Gene prediction in the Co homologous region of 'Golden Delicious' was virtually conducted by Velasco et al. (2010). All genes predicted in the region, including those listed in the consensus gene set and those predicted by FGENESH Arabidopsis, were downloaded from GDR for their CDS (coding sequences) and deduced protein sequences. Selection of the Co candidate genes was solely based on their putative functions in the predicted gene list. Phylogenetic analysis of the deduced protein sequences of the $C o$ candidate genes was performed using the MEGA4 program (Tamura et al. 2007).

\section{Results}

Segregation of growth habit

In population 'Fuji' $\times$ NYCO7-G (FN, 271 individuals), 156 and 104 trees were ranked as columnar (C) and standard (S) growth habit, respectively, and 11 trees were undetermined (Table 1). The growth habit segregation in this population was significantly distorted from the expected $1(\mathrm{C}): 1(\mathrm{~S})$ ratio $\left[P_{\left(d f=1, \chi^{2}>10.40\right)}=0.001\right]$ due to excessive columnars. Of the 222 genotypes in population 'Telamon' $x$ 'Braeburn' (TB), 105 were classified as columnar, 113 standard, and four were not determined. Chi-square test indicated that the growth habit segregation fits the expected ratio 1: $1\left[P_{\left(d f=1, \chi^{2}>0.29\right)}=0.59\right]$. Growth habit segregation in the small population 'Pinova' $x$ NYCO7-G (PN) also fits the expected $1(16 \mathrm{C}): 1(7 \mathrm{~S})$ ratio although the $P$ value is low $\left[P_{\left(d f=1, \chi^{2}>3.52\right)}=0.06\right]$ (Table 1). There was one genotype with ambiguous growth habit in population PN.

Table 2 Genomic sequence positions of the published Co-linked markers

\begin{tabular}{llll}
\hline Marker & Apple contig & Apple genome coordinates (contig) & Peach genome coordinates (marker) \\
\hline AU223548 & MDC011443.241 & Chr10: 16,985,072-17,006,359 & Scafold-8: 18,682,861-18,685,020 \\
SCAR682 & MDC011771.458 & Chr10: 17,535,637-17,544,447 & Scafold-8: 19,021,026-19,021,070 \\
CH03d11 & MDC015757.243 & Chr10: 18,197,057-18,229,728 & Scafold-8: 19,286,305-19,286,566 \\
EMPc105 & MDC035953.13 & Chr10: $18,556,885-18,580,918$ & Scafold-8: 19,453,116-19,456,249 \\
Hi01a03/Hi01b01 & MDC001120.265 & Chr10: 19,893,418-19,911,277 & \\
\hline
\end{tabular}


a

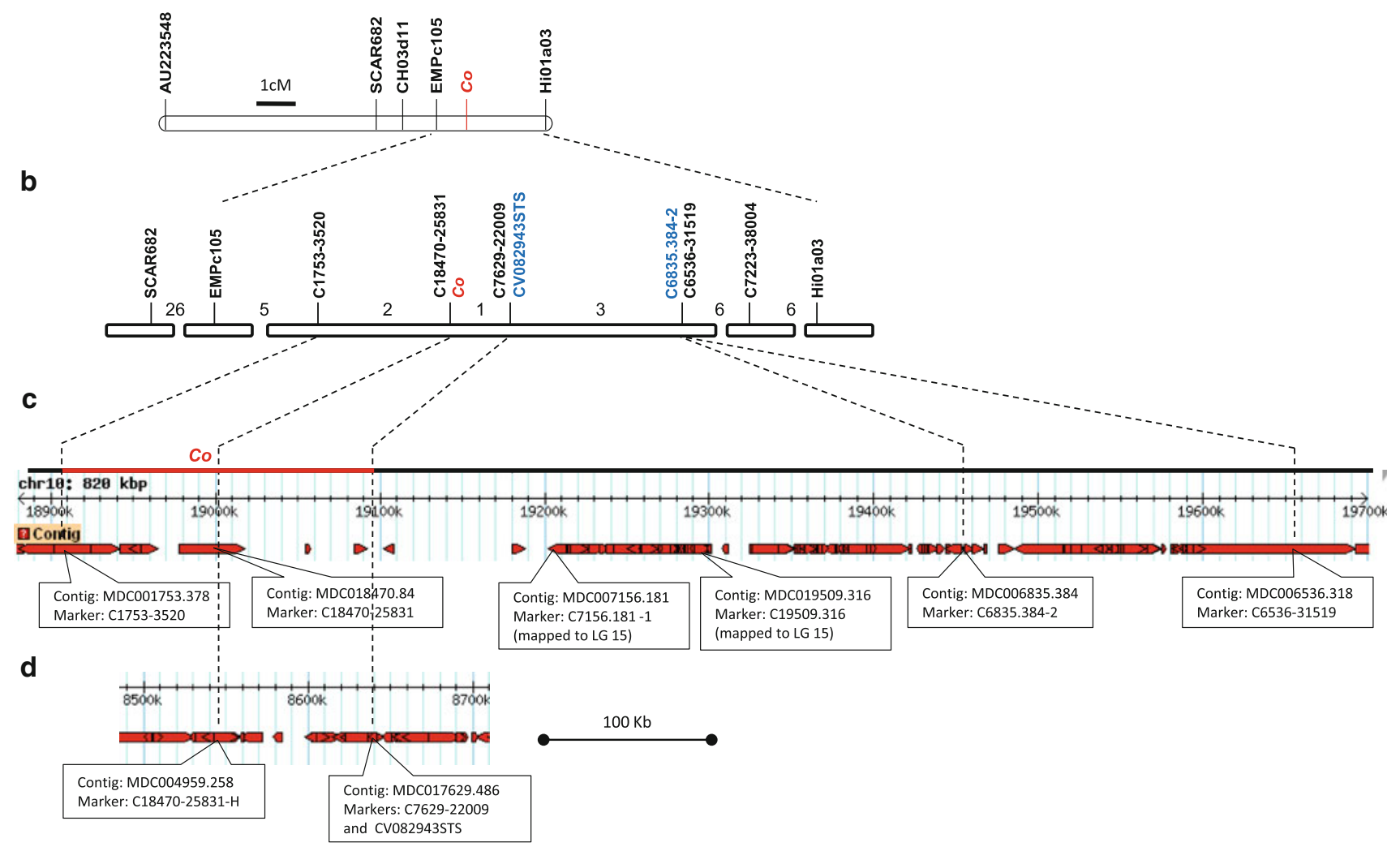

Fig. 1 Fine-scale genetic map of the Co locus on apple LG-10. a Initial map. Genetic distance (cM) between two adjacent markers is in accordance with the scale. b Fine-scale genetic map. The numbers between markers represent the number of recombinants identified out of 818 genotypes in the associated intervals. The genetic positions of markers CV082943STS (blue) and C6835.384-2 (blue) were deduced by their sequence physical locations relative to markers C7629-22009 or C6536-31519. c A $820 \mathrm{~kb}$ genome segment that spans over markers C1753-3520 and C6536-31519 on chromosome-10 of 'Golden Delicious' (a snapshot of a screen from the Genome Brower

Initial mapping of the Co locus

Screening of the 18 published markers (Online resource 3) with the ten columnar and ten standard segregants from population 'Fuji' $\times$ NYCO7-G, and/or the nine columnar and standard apple varieties/selections identified 6 markers that were strongly associated with Co: AU223548, SCAR682, CH03d11, EMPc105, Hi01a03 and Hi01b01. The last two markers produced nearly identical banding patterns (not shown). Closer examination showed that their primer sequences mostly overlapped, suggesting that they might represent the same marker. Therefore, only Hi01a03 was used in subsequent analyses, reducing the number of markers from six to five. Genotyping of these five markers in the three mapping populations showed that their segregation patterns were highly similar to that of columnar growth habit, i.e., fitting the expected $1: 1$ ratio in populations 'Telamon' $x$ 'Braeburn' $(\mathrm{TB})$ and 'Pinova' $\times$ NYCO7-G $(\mathrm{PN})$
(GB) at http://genomics.research.iasma.it/index.html (d was obtained from the same GB). Markers and associated source contigs are annotated. There is a large gap of nearly $200 \mathrm{~kb}$ forward from marker C18470-25831. The maximum Co region is shown with a red solid line. A segment of around $100 \mathrm{~kb}$, which includes two markers C7156.181-1 and C19509.316 that were mapped to LG-15 of PI 613988 in population GMAL 4595, appears to be assembled incorrectly here. d A $220 \mathrm{~kb}$ genome segment unanchored in the 'Golden Delicious' genome that spans over markers C18470-25831-H (an allele of C18470-25831) and C7629-22009 (color figure online)

while distorted in 'Fuji' $\times$ NYCO7-G $(\mathrm{FN}$, data not shown), implicating that the growth habit segregation distortion in population FN was caused by the segregation distortion of the $C o$ region. Linkage analyses were conducted using data pooled from the three populations ( $\mathrm{FN}, \mathrm{TB}$ and $\mathrm{PN}$ ) of 518 individuals in total. However, the 16 genotypes of undetermined growth habit (Table 1) in the pooled dataset of $\mathrm{Co}$ were treated with a missing value in the analysis. The results demonstrated that markers EMPc105 and Hi01a03 flank the Co locus by 0.8 and $2.1 \mathrm{cM}$, respectively (Fig. 1a; Online resource 3 ).

Molecular marker development and analysis

Marker development based on the peach genome: screening of the nine columnar and standard apple cultivars/ selections with the six Malus EST or Unigene derived SSR/ STS (sequence tagged sites) primers (Online resource 4) 
found no columnar specific bands, suggesting this approach to develop markers in the $C o$ region was not effective. One reason could be that the two apple ESTs (CN912694 and CN887623) tested were not the best matches for the two intended peach genes ppa019591m and ppa011712m (Online resource 4). However, the PCR amplicons generated by the STS primers of CV082943 (Table 3; Online resource 4) was polymorphic between 'Gala' and PI 613988, the two parents of population GMAL 4595 (Fig. 2). Analyzing the STS marker with population GMAL 4595 mapped CV082943STS between markers CH03d11 and Hi01a03 on LG-10 of PI 613988, suggesting that CV082943 represents an EST from the Co region. Marker Hi01a03 was not present in the published version of the PI 613988 map (Wang et al. 2012), but was added in this study. BLAST searches of the apple genome with the CV082943 sequence revealed that it is nearly identical to a part of a predicted gene MDP0000306656 in contig MDC017629.486 that has not been anchored (Table 3; Online resource 4). This suggests that contig MDC 017629.486 originates from the $C o$ region on chromosome10 and the synteny approach resulted in useful information for revising the current genome assembly around the $\mathrm{Co}$ locus.

Marker development based on the apple genome: representative contig sequences that cover most of the $1,354 \mathrm{~kb}$ Co region (with gaps) between markers EMPc105 and Hi01a03 on chromosome-10 were downloaded from GDR. Sequences in the some $160 \mathrm{~kb}$ region surrounding marker CV082943STS in the unanchored category of the 'Golden Delicious' genome were also similarly downloaded. Screening of these contigs using BatchPrimer3 identified a total of 36 contigs harboring at least one SSR, including 29 from chromosome-10 and 7 from the

Table 3 Name, primer sequence, fragment size and source contig of new markers developed around the Co locus

\begin{tabular}{|c|c|c|c|c|c|c|}
\hline Primer name & Primer sequence (for./rev.) & $\begin{array}{l}\text { Primer } \\
\text { type }\end{array}$ & Source contig & $\begin{array}{l}\text { Apple genome } \\
\text { coordinates }\end{array}$ & $\begin{array}{l}\text { Prod size } \\
\text { (bp) }\end{array}$ & SSR \\
\hline \multirow[t]{2}{*}{ C1753-3520 } & TCСCTCTCTTCTGTTGCAATTT & SSR & MDC01753.378 & $\begin{array}{l}\text { Chr10: } \\
18,901,668-18,941,510\end{array}$ & 176 & $(\mathrm{AT})_{21}$ \\
\hline & GGCTTAAAAGGGTTGAAGTTCTC & & & & & \\
\hline \multirow[t]{2}{*}{ C18470-25831 } & ACTCAAGGACTCTTGCCTGGT & SSR & MDC018470.84 & $\begin{array}{l}\text { Chr10: } \\
\quad 18,977,912-19,017,913\end{array}$ & 169 & $(\mathrm{TC})_{22}$ \\
\hline & CAACTCAATCTGCCCCAACTA & & & & & \\
\hline \multirow[t]{2}{*}{ C7629-22009 } & GGGCTAGCTGGCTAGGTGTA & SSR & MDC017629.486 & $\begin{array}{l}\text { Unanchored: } \\
7,665,498-7,688,729\end{array}$ & 184 & $(\mathrm{AG})_{22}$ \\
\hline & ACAACACACCCAGCCCTAAT & & & & & \\
\hline \multirow[t]{2}{*}{ CV082943STS $^{\mathrm{a}}$} & GCCATGCTCCTTCCATAAAA & STS & MDC017629.486 & $\begin{array}{l}\text { Unanchored: } \\
7,665,498-7,688,729\end{array}$ & 1479 & \\
\hline & AGGCCCACAGGATTTTTCTT & & & & & \\
\hline \multirow[t]{2}{*}{ C6835.384-2 $2^{\mathrm{b}}$} & AATTGAGCAAATACTCAAAGCATGT & SSR & MDC006835.384 & $\begin{array}{l}\text { Chr10: } \\
19,455,177-19,461,701\end{array}$ & 205 & $(\mathrm{AT})_{13}$ \\
\hline & GGATTGAGACGCATGGGTGA & & & & & \\
\hline \multirow[t]{2}{*}{ C6536-31519 } & TGGATGGTGGGATTTCTTGT & SSR & MDC006536.318 & $\begin{array}{l}\text { Chr10: } \\
\quad 19,590,008-19,693,186\end{array}$ & 196 & $(\mathrm{AG})_{19}$ \\
\hline & AAGGAAACCACATTGCCAAA & & & & & \\
\hline \multirow[t]{2}{*}{ C7223-38004 } & TCCACAACTAATCCCCATTTTT & SSR & MDC007223.300 & $\begin{array}{l}\text { Chr10: } \\
\quad 19,740,828-19,807,025\end{array}$ & 189 & $(\mathrm{TA})_{18}$ \\
\hline & AGCATGCATGGTCTTTACCC & & & & & \\
\hline \multirow[t]{2}{*}{ C7156.181-1 ${ }^{\mathrm{c}}$} & GACATTCCAAGATGTTCGGACAAA & SSR & MDC007156.181 & $\begin{array}{l}\text { Chr10: } \\
\quad 19,202,017-19,213,346\end{array}$ & 202 & $(\mathrm{AT})_{14}$ \\
\hline & TCGAGTTGGTCACTTCCCATGA & & & & & \\
\hline \multirow[t]{2}{*}{$\mathrm{C} 19509.316^{\mathrm{d}}$} & GGTGTTTTGTTCCCTTTTTAATTCC & SSR & MDC019509.316 & $\begin{array}{l}\text { Chr10: } \\
19,290,413-19,301,048\end{array}$ & 201 & $(\mathrm{AT})_{17}$ \\
\hline & CAATGAGGCTACGGCCCAAC & & & & & \\
\hline
\end{tabular}

a Mapped to LG-10 of PI 613988 (Wang et al. 2012). The reverse primer (AGGCCCACAGGATTTTTCTT) is directly derived from EST CV082943, but the forward primer (GCCATGCTCCTTCCATAAAA) is from UGID: 1640882 encompassing EST CV082943

b Mapped to LG-10 of PI 613988

c C7156.181 linked with marker C3740 on LG-15 of PI 613988

d C19509.316 linked with marker C4299 on LG15 of PI 613988 
Fig. 2 Agarose gel $(2.0 \%)$ profiles of marker CV082943STS. Lanes 1-9: CV082943STS PCR products amplified from nine apple cultivars/selections of columnar or standard growth habit (shown). Lane 10: $1 \mathrm{~kb}$ Plus DNA Ladder (Invitrogen, CA). Lane 11-25: CV082943STS PCR amplicons from the two parents and 13 progeny of population GMAL 4595 (Wang et al. 2012)

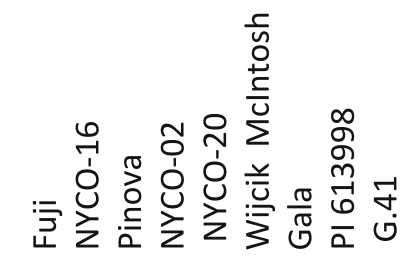

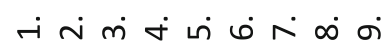

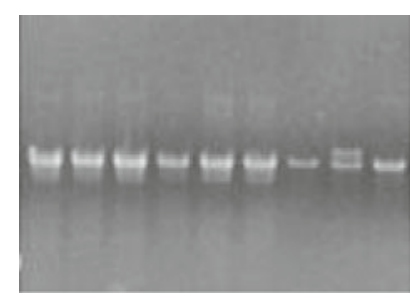

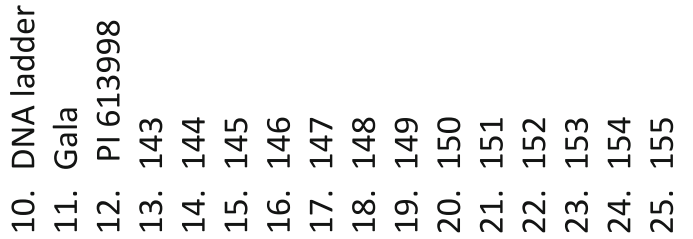

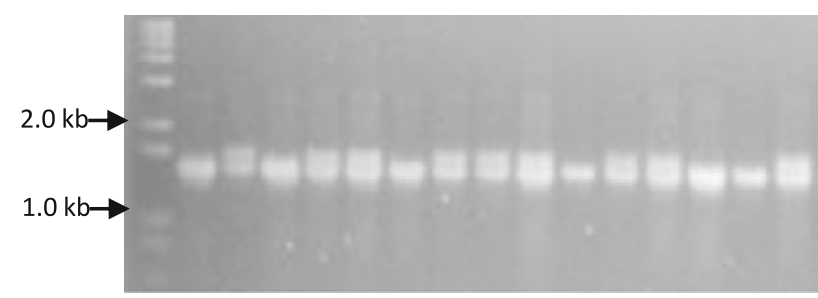

unanchored contigs, for which 67 and 21 SSR primer pairs (88 in total) were designed, respectively (Online resource 5). Evaluation of these SSR primers with the columnar/ standard cultivars, selections and segregants showed that five (C1753-3520, C18470-25831, C7629-22009, C653631519 and C7223-38004) generated columnar-specific bands (Fig. 3) although the majority was monomorphic. Fine mapping of these five SSR markers confirmed that their close linkage to Co (Fig. 1b). Marker C7629-22009 is derived from the unanchored contig MDC017629.486, in which marker CV082943STS resides.

Markers C6835.384-2, C7156.181-1 and C19509.316 produced no columnar-specific bands in the three mapping populations, but they were mapped in population GMAL 4595, similar to marker CV082943STS. As expected, marker C6835.384-2 closely linked to marker CV082943STS on LG-10 of PI 613988 (Table 3; Fig. 1c; Online resource 5), However, markers C7156.181-1 and C19509.316 were unexpectedly mapped to LG-15 of PI 613988 (Table 3; Fig. 1c; Online resources 5), with marker C7156.181-1 closely linked to marker C3740, and marker C19509.316 to marker C4299 (Wang et al. 2012), suggesting that contigs MDC007156.181 and MDC019509. 316 (Online resource 6), from which the two markers were derived, were likely incorrectly assembled to chromosome10 in the apple genome sequencing project (Velasco et al. 2010).

Construction of the fine map and estimation of the physical size at the Co locus

Based on the initial map of Co (Fig. 1a), two markers (SCAR682 and Hi01a03) were used to genotype the 290 columnar selections as well as the $\mathrm{F} \times \mathrm{T}$ population of 11 trees (Table 1). Together with the genotypic data obtained from the three populations of 517 trees (Table 1) in the initial mapping process, 47 informative recombinants were identified between the markers SCAR682 and Hi01a03. Of these recombinants, $10(3.7 \%)$ and $9(4.1 \%)$ were identified from populations $\mathrm{FN}$ and $\mathrm{TB}$, respectively, and 1 $(2.9 \%), 23(17.0 \%)$ and $4(3.3 \%)$ from the columnar selections CU, EMR and CAU, respectively. Overall, 20

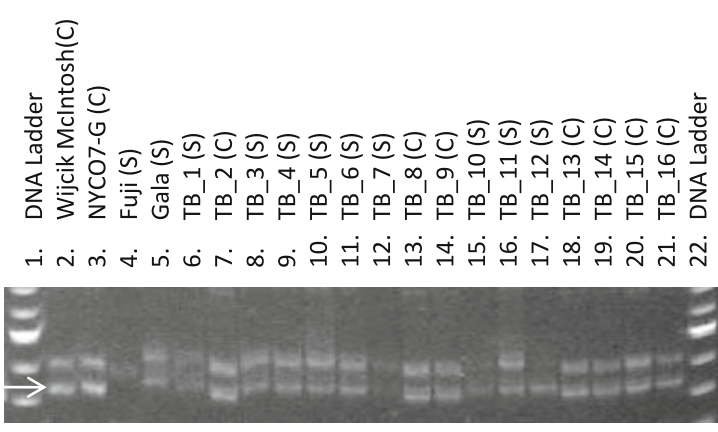

b

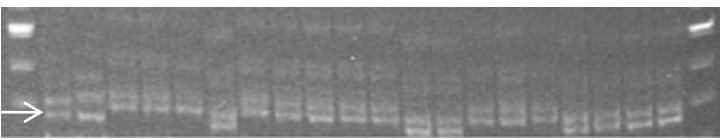

C

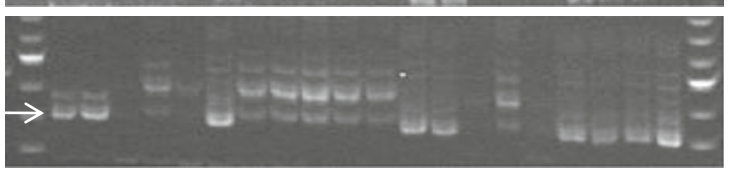

d

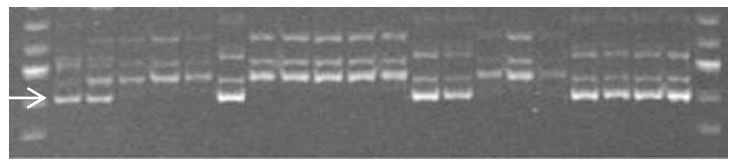

e

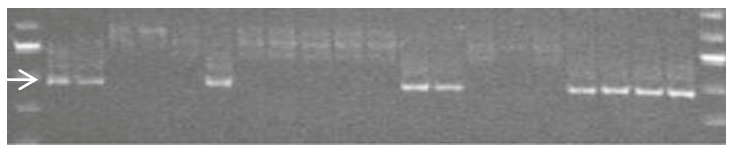

Fig. 3 Polyacrylamide gel profile of five SSR markers developed in the Co region. a C1753-3250. b C18470-25831. c C7629-22009. d C6536-31519. e C7223-38004. Lanes 1 and 22: 20 bp EZ Load Molecular Ruler (BioRad Cat \# 170-8201, Hercules, CA). Lanes 2-5: four columnar and standard apple varieties/selections as shown. Lanes 6-21: 16 progeny from population 'Telamon' $\times$ 'Braeburn'. Bands characteristic to a specific SSR marker are indicated with an arrow. $C$ columnar. $S$ standard 
recombinants arose from a $C$ allele (in coupling with allele $\mathrm{Co}$ ) at marker SCAR682 recombined with a $c$ (in coupling with allele $c o$ ) allele at marker Hi01a03, and 27 from a $c$ allele at marker SCAR682 with a $C$ allele at marker Hi01a03. There was one double-recombinant (CAUC10) between the two markers from the CAU columnar selections (Fig. 4).

Genotyping of the 47 single- and one doublerecombinant(s) with the five new SSR markers (C17533520, C18470-25831, C7629-22009, C6536-31519, C722338004) allowed the identification of six most informative recombinants (Fig. 4), enabling construction of a fine haploid map at the Co locus (Fig. 1b). Based on this map, the $C o$ locus was sandwiched by two flanking markers C1753-3520 (supported by two key recombinants EMRC-5 and EMRC-73) and C7629-22009 (supported by one key recombinant FN11-203) in an interval with a recombination frequency of $0.37 \%$ (3/818), and marker C1847025831 co-segregates with $C o$.

The physical size of the Co locus defined by the two immediate flanking markers C1753-3520 and C762922009 was estimated to be $193 \mathrm{~kb}$ (Fig. 1c, d; Online resource 6). The estimate was obtained from the sum of two genomic segments: one is from chromosome-10 of $98 \mathrm{~kb}$ between markers C1753-3520 and C18470-25831; the other from an unanchored segment of $95 \mathrm{~kb}$ between markers C7629-22009 and C18470-25831-H (a homologous sequence of marker C18470-25831, see below). The $95 \mathrm{~kb}$ unanchored segment includes contig MDC017629. 486 on one end and contig MDC004959.258 on the other. Contig MDC017629.486 was already mapped to the Co region based on markers C7629-22009 and CV082943STS. Contig MDC004959.258 was identified in the process intended to fill the large gap forward from contig MDC018470.84 (Fig. 1c) in the Co region. Evidence supporting contig MDC004959.258 of the origin at the Co locus includes the following. (1) Contig MDC004959.258 contains a sequence of $141 \mathrm{bp}$ highly identical to the SSR flanking sequences of marker C18470-25831 (169 bp in Golden Delicious), i.e., 68/73 and 38/41, respectively, suggesting that a homologous sequence of marker C1847025831, C18470-25831-H, is likely an allele of marker C18470-25831 (Online resource 7). (2) Contig MDC004959.258 $(26.1 \mathrm{~kb})$ shares high sequence identity with contig MDC018470.84 (40.0 kb), suggesting that MDC004959.258 may represent a homologous contig of MDC018470.84 (Online resource 7). (3) Contig MDC004959.258 is unanchored and located closely with the mapped contig MDC017629.486 (about $70 \mathrm{~kb}$ apart, Fig. 1d; Online resource 6).

Overall, the evidence also strongly suggests that the entire unanchored region between the two contigs MDC004959.258 and MDC017629.486 is originated from the $C o$ region. The genomic segment between markers C18470-25831-H and C7629-22009 was measured at $95 \mathrm{~kb}$ (Online resource 6), supporting the estimated $\mathrm{Co}$ region (between markers C1753-3520 and C7629-22009) of $193 \mathrm{~kb}$ in 'Golden Delicious' (Online resource 6).

\section{Predicted genes in the Co region}

In the $C o$ region of an estimate of $193 \mathrm{~kb}$ between markers C1753-3520 and C7629-22009, there are 26 genes predicted, including 12 from chromosome-10 (in consensus gene set) and 14 from the unanchored (include those in the consensus gene set and those predicted by FGENESH Arabidopsis) although there are several large gaps (Online resources 6 and 8). Based on the genome annotation (Velasco et al. 2010), the 26 genes comprise four 2OG-Fe(II) oxygenases, three LATERAL ORGAN BOUNDARIES

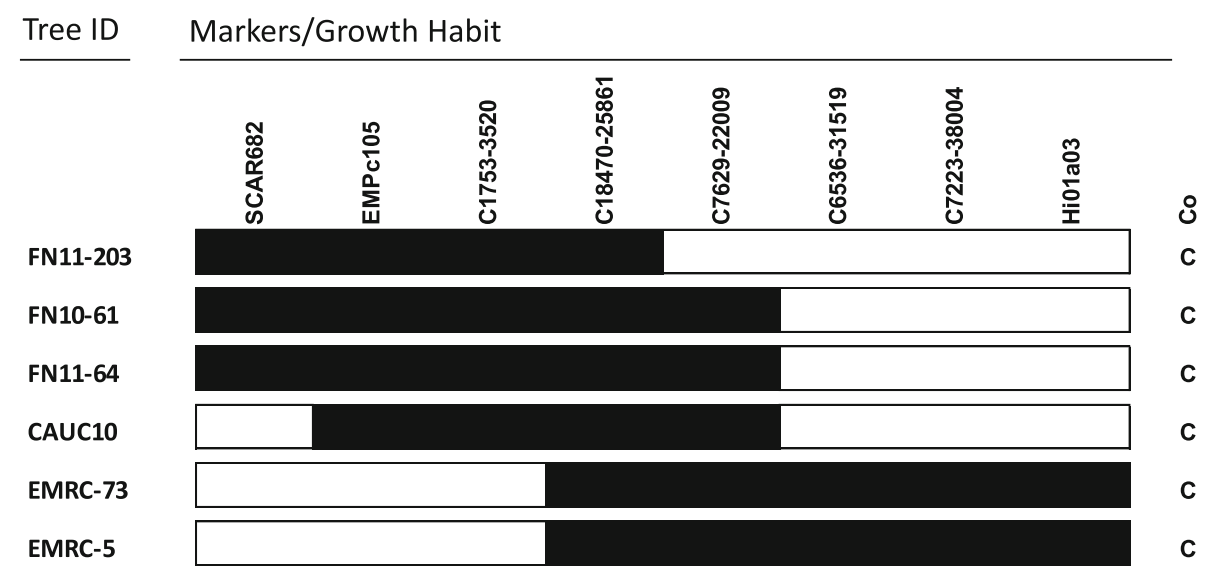

Fig. 4 Diagram of key recombinants in the $C o$ region. The solid bars represent chromosomal segments linked in coupling phase to the $C o$ allele conferring columnar growth habit from 'Wijcik McIntosh'. The open bars are for chromosomal segments associated with standard growth habit. The crossover break-points are shown by the junctions between the solid and open bars. Markers are positioned equidistantly irrespective to their genetic distance 
(LOB) DOMAIN (LBD) transcription factors, three pentatricopeptide repeat proteins, two carboxylesterases, two zinc ion binding proteins, one protein serine/threonine kinase, one hydrolase, six proteins without descriptions and four others (Online resources 6 and 8) (Velasco et al. 2010). The three putative LBD transcription factors, designated MdLBD1 (MDP0000174086), MdLBD2 (MDP 0000130894) and MdLBD3 (MDP0000131964), appear to be strong candidates for $\mathrm{CO}$ as studies in Arabidopsis and other plant species indicated that LBD proteins play important roles in the development of leaf, flower and roots, in meristem programming and in embryonic and vascular patterning (Majer and Hochholdinger 2011).

To understand the phylogenetic relationship with other known LBDs, the deduced protein sequences of MdLBD13 were analyzed together with the 42 LBD proteins encoded by the Arabidopsis genome (Matsumura et al. 2009). The results categorized the three MdLBDs into Class I Subtype C (Fig. 5). MdLBD1 and MdLBD2 are most closely related to ASL16/LBD29 (At3g58190), whereas MdLBD3 most to ASL18/LBD16 (At2g42430) (Figs. 5, 6).

\section{Discussion}

Plant materials and growth-habit evaluation

The genetic materials used in this study are diverse not only in their genetic background but also in the geographic locations where these materials were developed. To minimize the possible bias in evaluating growth habit, we choose to use only columnar selections from locations outside Geneva, New York, where both segregation populations and columnar selections were grown and evaluated. As these selections are selected by breeders for columnar apple development, their columnar growth habit is considered typical. Three segregation populations were evaluated over two consecutive years in Geneva, NY. A few intermediate types were difficult to determine and were
Fig. 5 Phylogenetic analysis of the three MdLBD proteins, candidates of $\mathrm{CO}$. Using the MEGA4 program (Tamura et al. 2007), the analysis was conducted on 46 LBD proteins. They include MdLBD1 (MDP0000174086), MdLBD2 (MDP0000130894), MdLBD3 (MDP0000131964), and 43 members from the LBD family of transcription factors in Arabidopsis (TAIR10), one (AT5G15060, tentatively named LBD43) more than the 42 members described in Matsumura et al. (2009). Their system used in classifying the LBD proteins (Matsumura et al. 2009) is adapted as presented. The tree is drawn to scale and the evolutionary distances are in the units of the number of amino acid substitutions per site

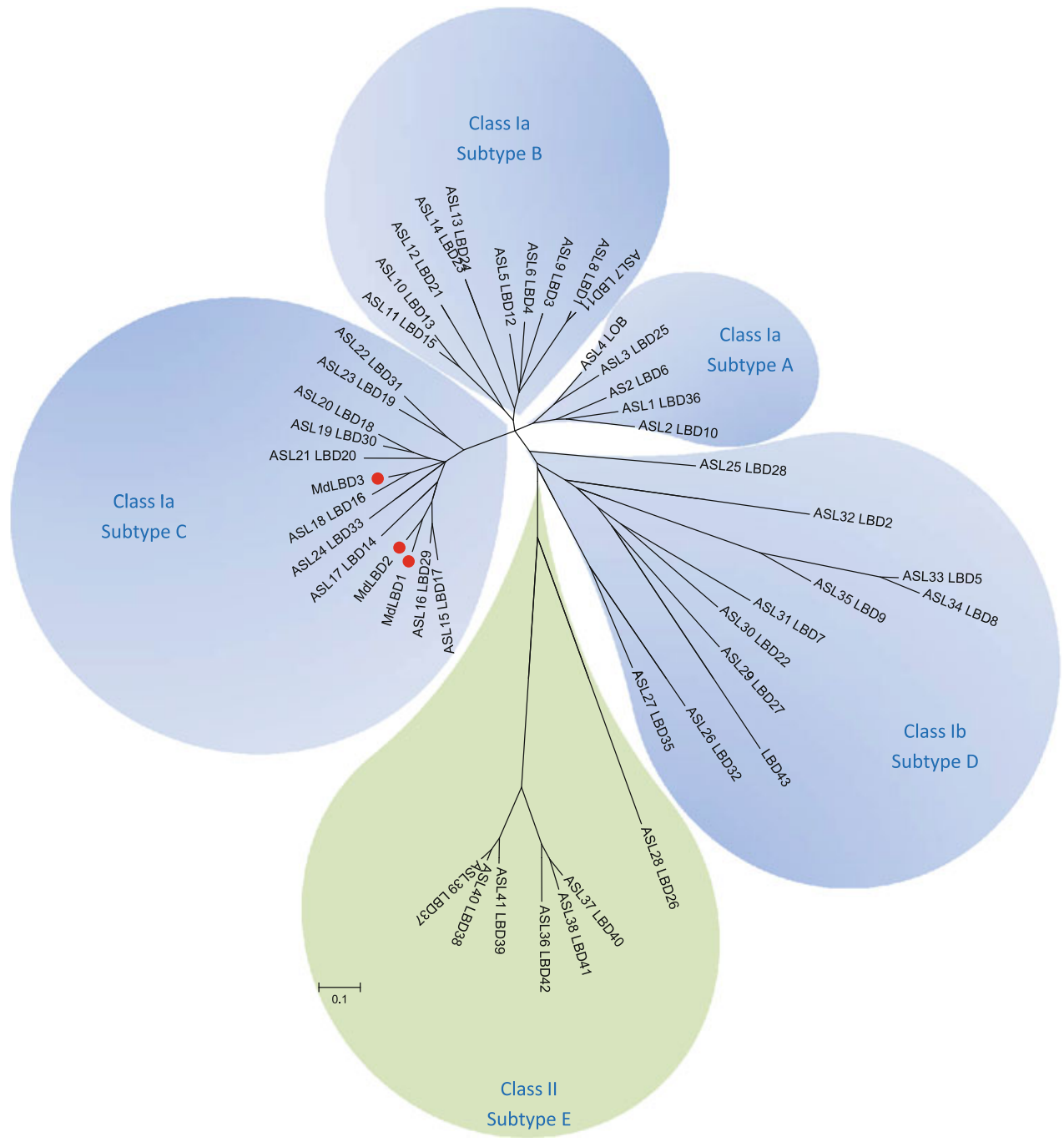




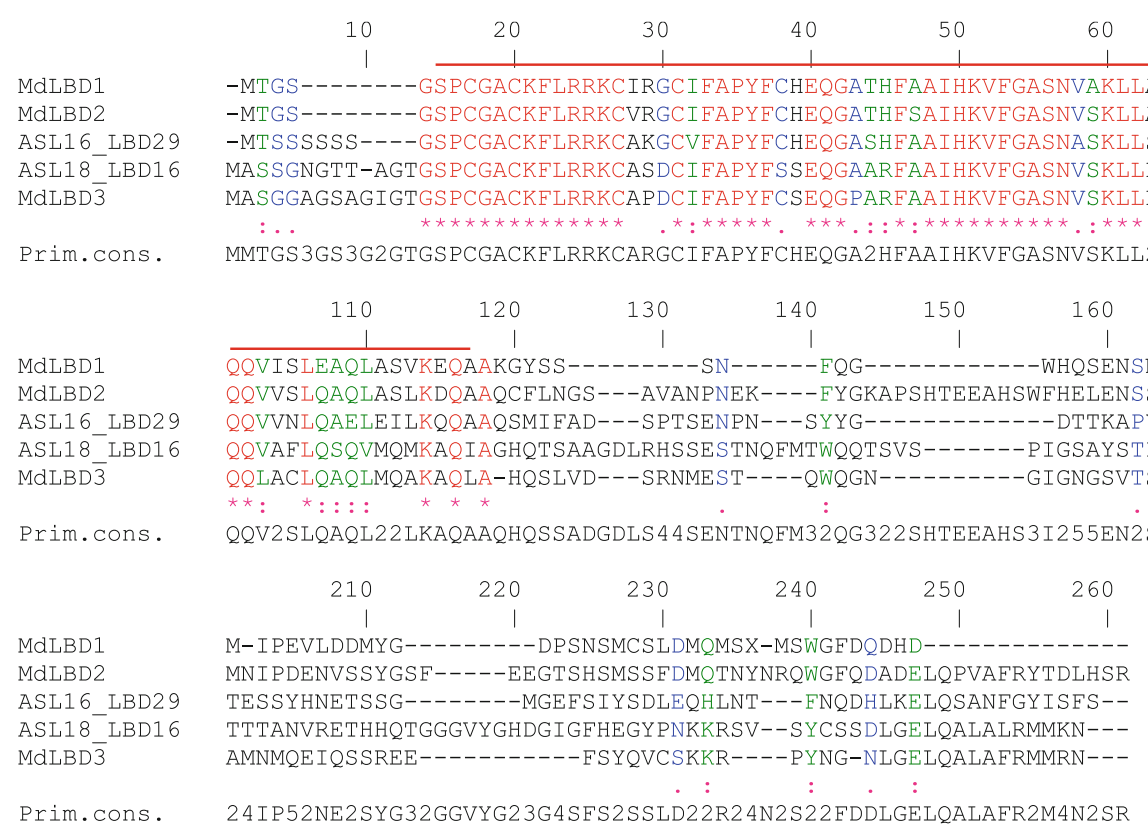

Fig. 6 Alignment of the deduced protein sequences of the three MdLBDs with two closest Arabidopsis LBDs (LBD16 and 29). The LOB domains are overlined as indicated in Matsumura et al. (2009)

removed from linkage analysis, but growth habit for most plants were scored with confidence.

Map position of the Co locus

In our initial mapping of the Co locus, five published markers (AU223548, SCAR682, CH03d11, EMPc105, and Hi01a03) generated polymorphic bands linked to the $C o$ allele in coupling phase, allowing construction of an initial Co allele specific map (Fig. 1a). This map placed $C o$ in an interval between markers EMPc105 and Hi01a03. Considering the previously published maps (Conner et al. 1997, 1998; Fernandez-Fernandez et al. 2008; Kenis and Keulemans 2007; Kim et al. 2003; Moriya et al. 2009; Tian et al. 2005; Zhu et al. 2007), the initial Co map is most comparable to the maps described by Moriya et al. (2009) based on the co-linearity of four common markers (AU223548, SCAR682, CH03d11 and Hi01a03). However, marker EMPc105 was not present in Moriya et al. (2009), but the relative marker positions between $\mathrm{CH} 03 \mathrm{~d} 11$ and EMPc105 were consistent with the map in FernandezFernandez et al. (2008) although they mapped Co on the other side of marker $\mathrm{CH} 03 \mathrm{~d} 11$. Based on the two common markers (CH03d11 and SCAR682), the initial map position of the $C o$ locus established in this study also appeared to be in agreement with that in Tian et al. (2005), which is more comparable with the maps in Moriya et al. (2009) according to the colinearity of three common markers (CH03d11, SCAR682 and SCAR216). The Co maps developed in other studies (Conner et al. 1997, 1998; Kenis and Keulemans 2007; Kim et al. 2003; Zhu et al. 2007) could not be compared due to the lack of common markers.

Marker development and fine mapping

We developed seven new SSR/STS markers that mapped to the expected Co region directly (for markers C1753-3520, C18470-25831, C7629-22009, C6536-31519 and C722338004) or indirectly (for markers CV082943STS and C6835.384-2) using the genome sequence information of apple and peach (Table 3; Fig. 1b-d; Online resources 4-6). Apple (sub-family Maloideae) and peach (sub-family Prunoideae) are genera in the Rosaceae family. Compared with apple, peach has a relative small diploid genome and the current version of peach genome (v1.0) has more complete coverage than the apple genome (v1.0). The synteny approach utilizing the peach genome led to the development of marker CV082943STS that was essential for the construction of the Co fine map. Marker CV082943STS enabled development of a key marker C7629-22009 flanking Co and provided evidence to prove an unanchored contig (MDC017629.486) that is, in fact, of the origin at the Co locus in apple. In addition, our sequence-based approach developed two markers (C7156.181-1 and C19509.316) that were mapped to LG-15 of PI 613988 (Wang et al. 2012), despite the source sequences were assembled to a physical position supposed to be close to or within the $C o$ region on chromosome-10 (Fig. 1c; Online resources 5). This unexpected development of the two markers might have helped correct an assembly error in the apple genome. 
The fine map was constructed by analyzing the five new SSR markers on 47 single- and one double-recombinant plants, among which six were key in ordering these markers (Fig. 4). Key recombinants FN11-203, FN10-61 and FN1164 are columnar segregants from population 'Fuji' $\times$ NYCO7-G, and CAUC10 is a double-recombinant and a columnar selection from 'Fuji' $\times$ Telamon (Table 1; Fig. 4). The pedigree of the remaining two, EMRC-5 and EMRC-73 that were developed by EMR (Fig. 4; Online resource 2), is complex: EMRC-5 is a columnar selection from the cross 'Red Sentinel' $\times$ SA723-17 ['Maypole' ('Wijcik McIntosh' $\times$ Malus 'Baskatong') $\times$ 'Dorothea'], whereas EMRC-73 from a hybridization of $\mathbf{S A 3 2 0 - 3}$ [SA54-290 (A1583 $\times$ 'Wijcik McIntosh' $) \times 3762] \times$ AR633-1, where the apple cultivars/selections in bold are columnar. This pedigree information suggested that the six key recombinants all probably inherited their columnar growth habit from 'Wijcik McIntosh'.

Recombinants FN11-203, EMRC-5 and EMRC-73 are the most informative in delimiting the Co region to the shortest interval between markers C1753-3520 and C762922009. Based on the deduced physical size of $193 \mathrm{~kb}$ (Fig. 1c, d; Online resource 6) for this genetic interval in the 'Golden Delicious' genome, the map restricted $C o$ to a manageable genomic segment to begin searching for the candidate genes of $\mathrm{Co}$. Our approach using diverse plant materials appeared to be a positive aspect in construction of the fine map as many more genotypes might have to be screened to narrow down the Co region to $193 \mathrm{~kb}$. Although we defined the $M a$ locus controlling apple fruit acidity to a $150 \mathrm{~kb}$ region using only 438 trees (Xu et al. 2011), the Co map developed from 818 genotypes is highly compared with the apple $V f$ fine map of $350 \mathrm{~kb}$ that required the analysis of 2,071 trees from seven $F_{1}$ populations (Patocchi et al. 1999; Vinatzer et al. 2001), and the rice $S u b 1$ fine map of $150 \mathrm{~kb}$ that was developed from more than $4,000 \mathrm{~F}_{2}$ plants (Xu et al. 2000, 2006). The high recombination frequency $(17.0 \%)$ in the EMR columnar selections, which was derived from a set of diverse parental lines (Online resource 2), was vital for the successful finescale mapping at the Co locus. One possible explanation for such high recombination rate in the EMR selections could be that some of the parents used in the pedigree might tend to generate gametes of higher crossover rate at the $C o$ locus. This appeared to be the case at the tomato $M i$ locus conferring root-knot nematode resistance where the recombination frequency varied by eightfold among different populations studied (Kaloshian et al. 1998).

Estimation of the physical size of the Co locus

The fine map defines the Co locus between two markers C1753-3520 and C7629-22009 with the former derived from contig MDC001753.378 on chromosome-10 and the latter from contig MDC017629.486 that is unanchored in the draft genome sequence of 'Golden Delicious' (Velasco et al. 2010). The unanchored contig MDC017629.486 encompasses CV082943, an apple EST orthologous to a peach gene ppa000811m found in a genomic region in Scaffold-8 presumably orthologous to the apple Co region (Online resource 4). Although CV082943 could not be mapped in the three mapping populations due to lacking of polymorphism, a CV082943 derived STS marker CV082943STS was mapped between markers CH03d11 and Hi01a03 on LG-10 of M. sieversii PI 613988 in population GMAL 4595 (Wang et al. 2012). These data, together with the independent SSR marker C7629-22009 developed directly from contig MDC017629.486, confirm that the unanchored MDC017629.486 originated from the Co region.

Estimation of the physical size of $193 \mathrm{~kb}$ at the Co locus between two markers C1753-3520 and C7629-22009 was conducted by combining a genomic segment from chromosome-10 of $98 \mathrm{~kb}$ between markers C1753-3520 and C18470-25831 and the other from an unanchored segment of $95 \mathrm{~kb}$ between markers C18470-25831-H and C762922009. There is no doubt that the $98 \mathrm{~kb}$ segment on chromosome-10 is of the Co locus origin. Important evidence in supporting that the $95 \mathrm{~kb}$ unanchored segment is also of the origin of the Co locus includes: (1) contig MDC017629.486 encompasses markers C7629-22009 and CV082943STS; (2) contig MDC004959.258 share high sequence identity with contig MDC018470.84 and contains marker C18470-25831-H (Online resource 7); (3) contig MDC004959.258 is placed only $70 \mathrm{~kb}$ apart from the mapped contig MDC017629.486 (Fig. 1d).

\section{Predicted genes in the $C o$ region}

There are 26 genes predicted in the Co region estimated of $193 \mathrm{~kb}$ between markers C1753-3520 and C7629-22009. Among them, the three putative LBD transcription factors, $M d L B D 1-3$, appear to be strong candidates for $C o$ based on the known functions of characterized LBD proteins in regulating lateral organ development in Arabidopsis and other plant species (Majer and Hochholdinger 2011). Phylogenetic analysis of the deduced protein sequences of MdLBD1-3, together with the 42 LBD proteins encoded by the Arabidopsis genome (Matsumura et al. 2009), categorizes the three MdLBDs into Class I Subtype C (Fig. 5). MdLBD1 and MdLBD2 are closely related to each other and resemble ASL16/LBD29 (At3g58190) the most while MdLBD3 is most similar to ASL18/LBD16 (At2g42430) (Figs. 5, 6). In a model of the auxin response factor (ARF)7- and ARF19-dependent auxin signaling cascade for lateral root formation, the activity of LBD16 and 
LBD29 directly leads to division of pericycle cells and lateral root initiation (Okushima et al. 2007). Given the known involvement of IAA in columnar growth habit (Watanabe et al. 2004, 2006, 2008), whether or not one, two or all of the three MdLBDs participate in controlling the growth and development of apple lateral branches, an important function of $\mathrm{CO}$, appears to be a promising future direction.

In summary, our research has resulted in a fine-scale genetic map at the Co locus. Based on this map, the Co locus co-segregates with marker C18470-25831 in an interval between markers C1753-3520 and C7629-22009 in the 818 genotypes studied. The five Co tightly linked SSR markers would be useful in marker assisted selection of columnar apples at the young seedling stage before planting. The physical size of the Co region defined by the two markers C1753-3520 and C7629-22009 was estimated to be $193 \mathrm{~kb}$ in the 'Golden Delicious' genome. There are 26 predicted genes in the $C o$ region, including the three LBD transcription factor genes $(M d L B D 1-3)$ that putatively play an important role in regulating lateral organ development in plant, which makes MdLBDI-3 strong candidates of $C o$. It would be of great interest to characterize the function of the Co candidate genes $M d L B D I-3$ in future to better understand the genetic and molecular control of columnar growth habit and tree architecture in apple.

Acknowledgments The authors would like to sincerely thank Dr. Kenneth Tobutt for his contributions to the development of the EMR columnar selections that were used in this study.

\section{References}

Baldi P, Komjanc M, Malnoy M, Magnago P, Costa F, Velasco R, Salvi S (2009) Toward cloning the apple columnar gene. Plant and animal genomes XVII conference (January 10-14, 2009), San Diego, CA

Bendokas V, Stanys V (2009) Variation of hormones in apple trees with different canopy architecture. Zemdirbyste (Agriculture) 96:76-82

Chaparro JX, Werner DJ, O’Malley D, Sederoff RR (1994) Targeted mapping and linkage analysis of morphological isozyme, and RAPD markers in peach. Theor Appl Genet 87:805-815

Conner PJ, Brown SK, Weeden NF (1997) Randomly amplified polymorphic DNA-based genetic linkage maps of three apple cultivars. J Am Soc Hortic Sci 122:350-359

Conner PJ, Brown SK, Weeden NF (1998) Molecular-marker analysis of quantitative traits for growth and development in juvenile apple trees. Theor Appl Genet 96:1027-1035

Costes E, Lauri PE, Regnard JL (2006) Analyzing fruit tree architecture: implications for tree management and fruit production. Hort Reviews 32:1-61

Cullings KW (1992) Design and testing of a plant-specific PCR primer for ecological and evolutionary studies. Mol Ecol $1: 233-240$

Davey MW, Kenis K, Keulemans J (2006) Genetic control of fruit vitamin C contents. Plant Physiol 142:343-351
Doyle JJ, Doyle JL (1987) A rapid DNA isolation procedure for small quantities of fresh leaf tissue. Phytochem Bull 19:11-15

Fernandez-Fernandez F, Evans KM, Clarke JB, Govan CL, James CM, Maric S, Tobutt KR (2008) Development of an STS map of an interspecific progeny of Malus. Tree Genet Genom 4:469-479

Hemmat M, Weeden NF, Conner PJ, Brown SK (1997) A DNA marker for columnar growth habit in apple contains a simple sequence repeat. J Am Soc Hortic Sci 122:347-349

Illa E, Sargent DJ, Girona EL, Bushakra J, Cestaro A, Crowhurst R, Pindo M, Cabrera A, van der Knaap E, Iezzoni A, Gardiner S, Velasco R, Arus P, Chagne D, Troggio M (2011) Comparative analysis of rosaceous genomes and the reconstruction of a putative ancestral genome for the family. BMC Evol Biol 11:9

Kaloshian I, Yaghoobi J, Liharska I, Hontelez J, Hanson D, Hogan P, Jesse T, Wijbrandi J, Simons G, Vos P, Zabel P, Williamson VM (1998) Genetic and physical localization of the root-knot nematode resistance locus $\mathrm{Mi}$ in tomato. Mol Gen Genet 257:376-385

Kenis K, Keulemans J (2005) Genetic linkage maps of two apple cultivars (Malus $\times$ domestica Borkh.) based on AFLP and microsatellite markers. Mol Breed 15:205-219

Kenis K, Keulemans J (2007) Study of tree architecture of apple (Malus $\times$ domestica Borkh.) by QTL analysis of growth traits. Mol Breed 19:193-208

Kenis K, Keulemans J, Davey M (2008) Identification and stability of QTLs for fruit quality traits in apple. Tree Genet Genom 4:647-661

Kim MY, Song KJ, Hwang JH, Shin YU, Lee HJ (2003) Development of RAPD and SCAR markers linked to the Co gene conferring columnar growth habit in apple (Malus pumila Mill.). J Hort Sci Bio 78:512-517

Lane WD, Looney NE, Mage F (1982) A selective tissue-culture medium for growth of compact (dwarf) mutants of apple. Theor Appl Genet 61:219-223

Lapins KO (1969) Segregation of compact growth types in certain apple seedling progenies. Can J Plant Sci 49:765-768

Lapins KO (1976) Inheritance of compact growth type in apple. J Am Soc Hortic Sci 101:133-135

Lespinasse JM, Delort JF (1986) Apple tree management in vertical axis: appraisal after ten years of experiments. Acta Hort 160:139-156

Liebhard R, Gianfranceschi L, Koller B, Ryder CD, Tarchini R, Van de Weg E, Gessler C (2002) Development and characterisation of 140 new microsatellites in apple (Malus $\times$ domestica Borkh.). Mol Breed 10:217-241

Looney NE, Lane WD (1984) Spur-type growth mutants of McIntosh apple: a review of their genetics, physiology and field performance. Acta Hort 146:31-46

Majer C, Hochholdinger F (2011) Defining the boundaries: structure and function of LOB domain proteins. Trends Plant Sci $16: 47-52$

Matsumura Y, Iwakawa H, Machida Y, Machida C (2009) Characterization of genes in the ASYMMETRIC LEAVES2/LATERAL ORGAN BOUNDARIES (AS2/LOB) family in Arabidopsis thaliana, and functional and molecular comparisons between AS2 and other family members. Plant J 58:525-537

Moriya S, Iwanami H, Kotoda N, Takahashi S, Yamamoto T, Abe K (2009) Development of a marker-assisted selection system for columnar growth habit in apple breeding. J Jpn Soc Hortic Sci 78:279-287

Okushima Y, Fukaki H, Onoda M, Theologis A, Tasaka M (2007) ARF7 and ARF19 regulate lateral root formation via direct activation of LBD/ASL genes in Arabidopsis. Plant Cell 19:118-130

Patocchi A, Vinatzer BA, Gianfranceschi L, Tartarini S, Zhang HB, Sansavini S, Gessler C (1999) Construction of a $550 \mathrm{~kb}$ BAC 
contig spanning the genomic region containing the apple scab resistance gene $V f$. Mol Gen Genet 262:884-891

Pereira-Lorenzo S, Ramos-Cabrer AM, Fischer M (2009) Breeding apple (Malus $\times$ domestica Borkh). In: Jain SM, Priyadarshan PM (eds) Breeding plantation tree crops: temperate species. Springer, Heidelberg, pp 1-49

Rajapakse S, Belthoff LE, He G, Estager AE, Scorza R, Verde I, Ballard RE, Baird WV, Callahan A, Monet R, Abbott AG (1995) Genetic linkage mapping in peach using morphological, RFLP and RAPD markers. Theor Appl Genet 90:503-510

Sajer O, Scorza R, Dardick C, Zhebentyayeva T, Abbott AG, Horn R (2011) Development of sequence-tagged site markers linked to the pillar growth type in peach (Prunus persica). Plant Breed. doi:10.1111/j.1439-0523.2011.01912.x. (Published online)

Sarwar M, Skirvin RM, Kushad M, Norton MA (1998) Selecting dwarf apple (Malus $\times$ domestica Borkh) trees in vitro: multiple cytokinin tolerance expressed among three strains of 'McIntosh' that differ in their growth habit under field conditions. Plant Cell Tiss Org 54:71-76

Scorza R, Bassi D, Liverani A (2002) Genetic interactions of pillar (columnar), compact, and dwarf peach tree genotypes. J Am Soc Hortic Sci 127:254-261

Segura V, Cilas C, Costes E (2008) Dissecting apple tree architecture into genetic, ontogenetic and environmental effects: mixed linear modelling of repeated spatial and temporal measures. New Phytol 178:302-314

Segura V, Durel CE, Costes E (2009) Dissecting apple tree architecture into genetic, ontogenetic and environmental effects: QTL mapping. Tree Genet Genom 5:165-179

Silfverberg-Dilworth E, Matasci CL, Van de Weg WE, Van Kaauwen MPW, Walser M, Kodde LP, Soglio V, Gianfranceschi L, Durel CE, Costa F, Yamamoto T, Koller B, Gessler C, Patocchi A (2006) Microsatellite markers spanning the apple (Malus $\times$ domestica Borkh.) genome. Tree Genet Genom 2:202-224

Sosinski B, Gannavarapu M, Hager LD, Beck LE, King GJ, Ryder CD, Rajapakse S, Baird WV, Ballard RE, Abbott AG (2000) Characterization of microsatellite markers in peach [Prunus persica (L.) Batsch]. Theor Appl Genet 101:421-428

Tamura K, Dudley J, Nei M, Kumar S (2007) MEGA4: Molecular evolutionary genetics analysis (MEGA) software version 4.0. Mol Biol Evol 24:1596-1599

Tian Y-K, Wang C-H, Zhang J-S, James C, Dai H-Y (2005) Mapping $\mathrm{Co}$, a gene controlling the columnar phenotype of apple, with molecular markers. Euphytica 145:181-188

Tobutt KR (1984) Breeding columnar apple varieties at East Malling. Sci Horti 35:72-77

Van Ooijen JW, Voorrips RE (2001) JoinMap ${ }^{\circledR}$ 3.0: software for the calculation of genetic linkage maps. Plant Research International, Wageningen

Velasco R, Zharkikh A, Affourtit J, Dhingra A, Cestaro A, Kalyanaraman A, Fontana P, Bhatnagar SK, Troggio M, Pruss D, Salvi S, Pindo M, Baldi P, Castelletti S, Cavaiuolo M, Coppola G, Costa F, Cova V, Dal Ri A, Goremykin V, Komjanc
M, Longhi S, Magnago P, Malacarne G, Malnoy M, Micheletti D, Moretto M, Perazzolli M, Si-Ammour A, Vezzulli S, Zini E, Eldredge G, Fitzgerald LM, Gutin N, Lanchbury J, Macalma T, Mitchell JT, Reid J, Wardell B, Kodira C, Chen Z, Desany B, Niazi F, Palmer M, Koepke T, Jiwan D, Schaeffer S, Krishnan V, Wu C, Chu VT, King ST, Vick J, Tao Q, Mraz A, Stormo A, Stormo K, Bogden R, Ederle D, Stella A, Vecchietti A, Kater MM, Masiero S, Lasserre P, Lespinasse Y, Allan AC, Bus V, Chagne D, Crowhurst RN, Gleave AP, Lavezzo E, Fawcett JA, Proost S, Rouze P, Sterck L, Toppo S, Lazzari B, Hellens RP, Durel C-E, Gutin A, Bumgarner RE, Gardiner SE, Skolnick M, Egholm M, Van de Peer Y, Salamini F, Viola R (2010) The genome of the domesticated apple (Malus $\times$ domestica Borkh.). Nat Genet 42:833-839

Vinatzer BA, Patocchi A, Gianfranceschi L, Tartarini S, Zhang HB, Gessler C, Sansavini S (2001) Apple contains receptor-like genes homologous to the Cladosporium fulvum resistance gene family of tomato with a cluster of genes cosegregating with $V f$ apple scab resistance. Mol Plant Microbe In 14:508-515

Wang A, Aldwinckle H, Forsline P, Main D, Fazio G, Brown S, Xu K (2012) EST contig-based SSR linkage maps for Malus $\times$ domestica cv Royal Gala and an apple scab resistant accession of $M$. sieversii, the progenitor species of domestic apple. Mol Breed 29:379-397

Watanabe M, Suzuki A, Komori S, Bessho H (2004) Comparison of endogenous IAA and cytokinins in shoots of columnar and normal type apple trees. J Jpn Soc Hortic Sci 73:19-24

Watanabe M, Suzuki A, Komori S, Bessho H (2006) Effects of heading-back pruning on shoot growth and IAA and cytokinin concentrations at bud burst of columnar-type apple trees. J Jpn Soc Hortic Sci 75:224-230

Watanabe M, Bessho H, Suzuki A, Komori S (2008) Seasonal changes of IAA and cytokinin in shoots of columnar type apple trees. Acta Hort 774:75-80

Werner DJ, Chaparro JX (2005) Genetic interactions of pillar and weeping peach genotypes. HortScience 40:18-20

Xu K, Xu X, Ronald PC, Mackill DJ (2000) A high-resolution linkage map in the vicinity of the rice submergence tolerance locus Sub1. Mol Gen Genet 263:681-689

Xu K, Xu X, Fukao T, Canlas P, Maghirang-Rodriguez R, Heuer S, Ismail AM, Bailey-Serres J, Ronald PC, Mackill DJ (2006) Sub1A is an ethylene-response-factor-like gene that confers submergence tolerance to rice. Nature 442:705-708

Xu K, Wang A, Brown S (2011) Genetic characterization of the $M a$ locus with $\mathrm{pH}$ and titratable acidity in apple. Mol Breed. doi: 10.1007/s11032-011-9674-7

You F, Huo N, Gu Y, Luo M-c, Ma Y, Hane D, Lazo G, Dvorak J, Anderson O (2008) BatchPrimer3: a high throughput web application for PCR and sequencing primer design. BMC Bioinform 9:253

Zhu YD, Zhang W, Li GC, Wang T (2007) Evaluation of inter-simple sequence repeat analysis for mapping the Co gene in apple (Malus pumila Mill.). J Hortic Sci Bio 82:371-376 